\title{
INTRAOCULAR MALIGNANT TERATOID MEDULLOEPITHELIOMA
}

\author{
Adhikari $\mathbf{R} \mathbf{C}^{1}$, Sainju $\mathbf{R}^{1}$, Sayami $\mathrm{G}^{1}$, Dali $\mathrm{S}^{1}$, \\ Shrestha $\mathrm{H} \mathrm{G}^{1}$, Basnet $\mathrm{R} \mathrm{B}^{2}$, Pandey $\mathrm{J} \mathrm{S}^{3}$
}

\section{ABSTRACT}

Malignant teratoid medulloepithelioma is an uncommon unilateral intraocular tumor, occuring typically in children. This report concerns a 4-year-old boy, who presented with loss of vision, pain and proptosis of the left eye and showed mass in between eyelids. Histopathologically, the tumor was composed of pseudostratified primitiveappearing epithelium dispersed in cords, strands, tubules \& glands, which were separated by a cystic spaces, filled with pale eosinophilic material. Foci of glial tissue, cartilage, bone, skeletal muscle and fatty tissue were recognized. In addition, scleral extension of tumor, Homer-Wright like and Flexner-Wintersteiner like rosettes and foci of necrosis were also present. The differentiation from retinoblastoma was discussed.

Key Words: Malignant medulloepithelioma, eyeball, heteroplasia.

\section{INTRODUCTION}

Intraocular teratoid medulloepitheliomas are very rare embryonal tumors that usually originate from the ciliary epithelium ${ }^{1-7}$ and rarely from the iris, ${ }^{8}$ retina ${ }^{9,15}$ or optic nerve. ${ }^{10}$ Medulloepithelioma is an unilateral ocular tumor, ${ }^{8}$ typically found in children. It accounts for almost all the tumors in the congenital group, but they are much rarer than retinoblastomas, which are believed to be congenital tumors of the retina. Medulloepitheliomas can be classified according to the WHO as medulloepithelioma or teratoid medulloepithelioma, benign or malignant. The teratoid variant shows heteroplasia with areas of hyaline cartilage, rhabdomyoblasts, undifferentiated mesenchymal tissue or neuroglial tissue. Clinical presentations include poor vision

1. TU Teaching Hospital, Maharajgunj, Kathmandu, Nepal.

2. Bir Hospital, Kathmandu, Nepal.

3. Birendra Army Hospital, Chhauni, Kathmandu, Nepal.

Address for correspondence : Dr. Ram Chandra Adhikari

Lecturer, Dept. of Pathology

T. U. Teaching Hospital, Maharajgunj, Kathmandu, Nepal.

Email: rcadhikari@hotmail.com 
\& pain; white pupil, ${ }^{11}$ a mass in the iris, anterior chamber or ciliary body, glaucoma, ${ }^{12}$ cataract,,${ }^{13}$ lens coloboma, ${ }^{13}$ iris neovascularization, ${ }^{13}$ ectopia lentis. ${ }^{14}$ proptosis etc.

This case intraocular malignant teratoid medulloepithelioma is herewith reported for its rarity.

\section{CASE HISTORY}

The patient was a four year old boy, who presented with loss of vision, pain and proptosis of the left eye since last 2 yrs. Later on, proptosis had been progressed and a mass appeared inbetween eyelids. This mass slowly enlarged in size and presented as fungating mass since last 2 weeks.

On examination left eye showed fungating mass, with superficial necrosis. Right eye was apparently normal. No family member or relatives have been diagnosed to have eye tumors in the past. Systemic examination didn't reveal any abnormalities. No regional lymphadenopathies were noticed. Routine blood examination revealed $\mathrm{Hb}-10.7 \mathrm{gm} / \mathrm{dl}$; WBC$9,400 / \mathrm{cmm}$ with $55 \%$ neutrophils, $41 \%$ lymphocytes, $3 \%$ monocytes and $1 \%$ eosinophils; ESR $-17 \mathrm{~mm} / 1^{\text {st }}$ hour. Ultrasound scanning of the abdomen (liver, gall bladder, spleen, pancreas) were normal. The case was clinically diagnosed as retino-blastoma. As there was a large fungating eyeball mass, protruding inbetween eyelids and vision on this eye was completely absent; the exenteration was carried out.

\section{HISTOPATHOLOGICAL FINDINGS}

Gross: Exenteration specimen consisted of eyelids and an eyeball, replaced by a mass, which extended beyond the limits of eyelids. Mass was grey-white $\&$ soft, measured $5 \mathrm{~cm} \times 5 \mathrm{~cm} \times 3 \mathrm{~cm}$. It had irregular border and was attached to the wall of eyeball in the region of ciliary body. Cut surface showed areas of haemorrhage \& necrosis.

Microscopic: Tumor was composed of pseudostratified primitive-appearing epithelium dispersed in cords, strands, tubules \& glands (fig.1).

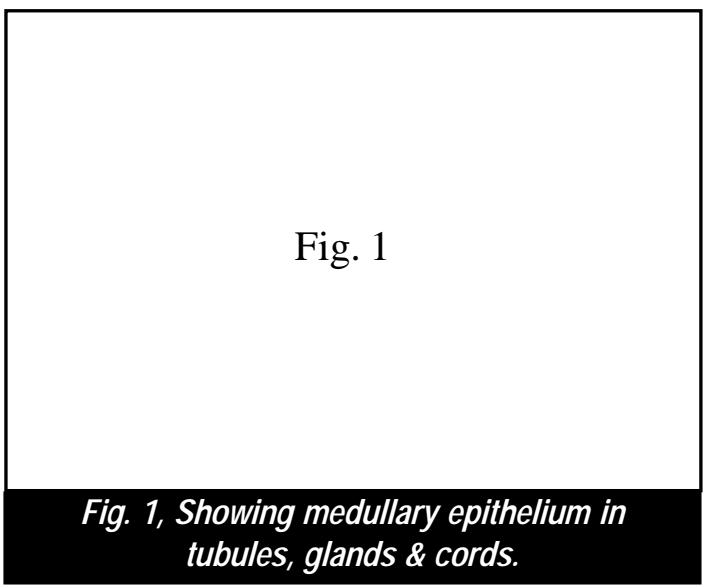

These structures were separated by a cystic spaces, filled with pale eosinophilic material (fig.2).The

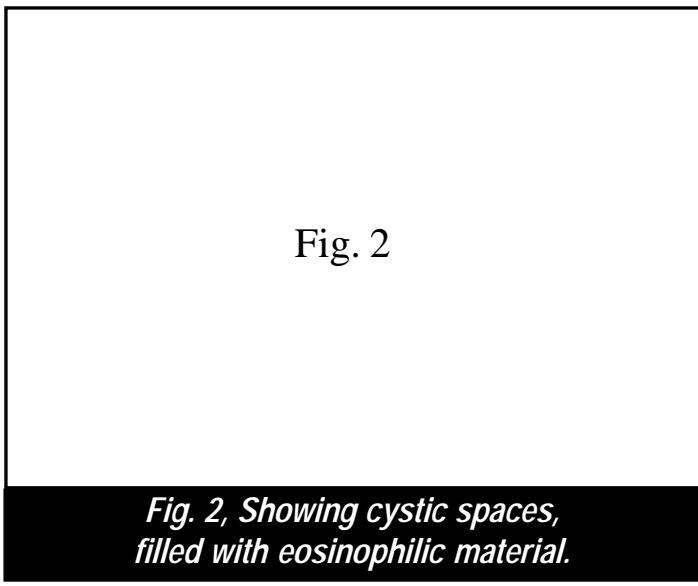

cells were pleomorphic, columnar shaped with few mitoses. In addition, there were foci of glial tissue (fig.3), cartilage (fig.4), bone (fig.5) skeletal muscle and fatty tissue. There was extension of tumor to the sclera. A few Homer-Wright like and FlexnerWintersteiner like rosettes (fig.6) were also present. There were areas of focal necrosis. So, histopathological diagnosis of malignant teratoid medulloepithelioma was made. 


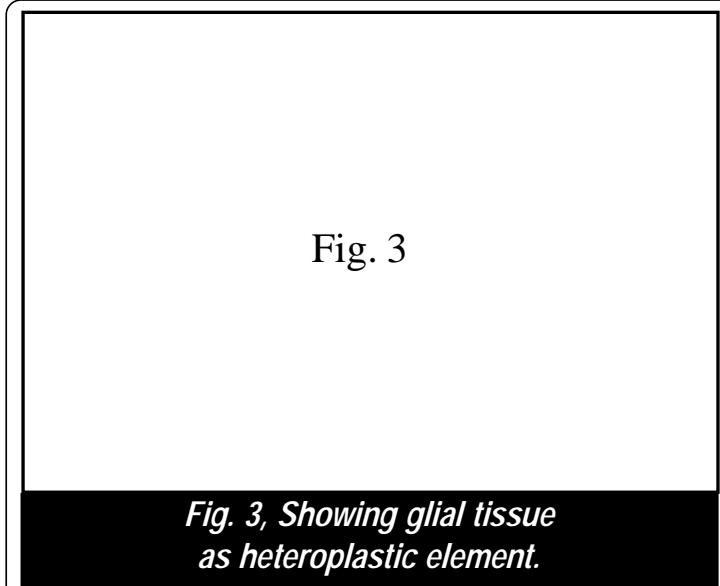

Fig. 6

\section{Fig. 6, Showing Homer - Wright like \& Flexner - Wintersteiner like rosettes.}

\section{DISCUSSION}

Verhoeff ${ }^{(9)}$ in 1904 gave the first detailed histological description of a medulloepithelium, but he named the tumor a "teratoneuroma" despite the fact that its histology was not teratomatous. In 1908, Fuchs ${ }^{16}$ coined the term "diktyoma" to describe netlike pattern of interlacing ribbons of poorly differentiated neuroepithelial cells. The term "medulloepithelioma" was probably first used for this tumor by Grinker" in 1931.

Fig. 4, Showing lobules of cartilage as heteroplastic element.

Medulloepitheliomas are neoplasms containing multilayered sheets $\&$ cords of poorly differentiated neuroepithelial cells. These sheets \& cords often fold back upon themselves so that structures of varying shapes \& sizes are formed. The proliferating medullary epithelium may form intricately anastomosing cords \& sheets separated by cystic spaces (containing hyaluronic acid) producing net-like appearance. ${ }^{4}$ Homer-Wright and Flexner-Wintersteiner rosettes may also be observed. Our case was typical and we found all these histological features. The heteroplastia is observed in teratoid medulloepitheliomas. The heteroplastic elements include hyaline cartilage, ${ }^{4,17}$ rhabdomyoblasts, ${ }^{4,17}$ undifferentiated mesenchymal cells, ${ }^{17}$ neural tissue ${ }^{4}$ etc. The common heteroplastic element is hyaline cartilage. In our case, the

Fig. 5, Showing bony tissue as heteroplastic element. 
observed heteroplastic elements were hyaline cartilage, glial tissue, bony tissue, fatty tissue and skeletal muscle. The medulloepithelioma is considered as malignant ${ }^{9}$ if it contains areas composed of poorly differentiated neuroblastic cells with greater pleomophism \& mitotic figures and/ or sarcomatous areas resembling rhabdomyosarcoma, chondrosarcoma or embryonal sarcoma. Invasion of uvea, cornea or sclera with or without extraocular extension is also criterion for malignancy. In our case, we found poorly differentiated neuroblastic cells with scleral extension, few Homer- Wright like and FlexnerWintersteiner like rosettes. However, sarcomatous areas were not observed. Electron microscopically ${ }^{18}$ the lumens of the rosettes contain slender microvilli, bordered by terminal bar complexes. Zonula adherens and zonula occludens type juctions are also evident. Electron microscopic study was not done in our case. Immunohistochemically ${ }^{19}$ the neuroepithelial tumor cells were positive for neuron-specific enolase, vimentin and often for S-100 protein; and the neuroblastic cells for neuron-specific enolase and synaptophysin. Immunohistochemical study was not done in our case.

Clinically poor vision, pain, mass in iris or ciliary body, proptosis and leukocoria are common features. Our case presented with loss of vision, pain and proptosis of eyeball. The treatment of intraocular medulloepithelioma is surgery i.e. local excision, enucleation or exenteration. ${ }^{4}$ Radiation appears to have no effect. In our case, exenteration was carried out and patient was lost to follow-up.

Distinction from the common ocular tumor of childhood, the retinoblastoma may be sometimes difficult clinically as well as histopathologically. Medulloepithelioma differs from the retinoblastoma by a later age of onset, anterior development, a frequent cystic structure and presence of heteroplastic elements..$^{20,21}$

This case report emphasizes the fact that intraocular medulloepithelioma should be considered as a differential diagnosis for an eyeball mass.

\section{REFERENCES}

1. Charif Chefchaouni M, El Bakkali M, Abdellah H, El Amarti A, Benchrifa F, Saidi O, Berraho A. Medulloepithelioma of the ciliary body. A case report. J Fr Ophtalmol 2000;23:165-9.

2. Husain SE, Husain N, Boniuk M, Font RI. Malignant nonteratoid medulloepithelioma of the ciliary body in an adult. Ophthalmology 1998; 105:596-9.

3. Shields JA, Eagle RC J r, Shields CL, Potter PD. Congenital neoplasms of the nonpigmented ciliary epithelium. Ophthalmology 1996; 103:19982006.

4. Monchy $D$, J acquiot $P$, Dubourdieu $D$, Huerre $M$. Malignant teratoid medulloepithelioma of the ciliary body. Apropos of a case and review of the literature. Arch Anat Cytol Pathol 1993;41:107-12.

5. Hausmann N, Stefani FH. Medulloepithelioma of the ciliary body. Acta Ophthalmol 1991;69:398-401.

6. Francois $P$, Castier $P$, Woillez M, Boursier C. Eye medulloepithelioma. Apropos of 2 cases. Bull Soc Ophtalmol Fr 1989; 89:1009-11.

7. Brownstein S, Barsoum-Homsy M, Conway VH, Sales C, Condon G. Nonteratoid medulloepithelioma of the ciliary body. Ophthalmology 1984;91:1118-22.

8. Myron Y, Ben SF. Ocular pathology.3rd edition.1989:504.

9. Broughton W, Zimmerman L. A clinicopathologic study of 56 cases of intraocular medulloepitheliomas. Am J Ophthalmol 1978;85:407-18.

10. O'Keefe M, Fulcher T, Kelly P, Lee W, Dudgeon J . medulloepithelioma of the optic nerve head. Arch Ophthalmol 1997;115:1325-7.

11. Lloyd WC 3rd, O'Hara M. Malignant teratoid medulloepithelioma: clinical-echographic- 
histopathologic correlation. J AAPOS 2001;5:395-7.

12. Katsushima H, Suzuki J, Adachi J, Nakagawa T, Satoh M. Non-rubeotic angle-closure glaucoma associated with ciliary medulloepithelioma. J pn J Ophthalmol 1996; 40:244-50.

13. Singh $A$, Singh $A D$, Shields $C L$, Shields J A. Iris neovascularization in children as a manifestation of underlying medulloepithelioma. J Pediatr Ophthalmol Strabismus 2001;38:224-8.

14. Gupta NK, Simon JW, Walton Ds, Augsburger JJ . Bilateral ectopia lentis as a presenting feature of medulloepithelioma. J AAPOS 2001;5:255-7.

15. Vadmal M, Kahn E, Finger P, Teichberg S. Nonteratoid medulloepithelioma of the retina with electron microscopic and immunohistochemical characterization. Pediatr Pathol Lab Med 1996; 16:663-72.

16. Naumann GOH, Apple DJ.Pathology of the eye.1986:668-9.
17. Pe'er J, Hidayat AA. Malignant teratoid medulloepithelioma manifesting as a black epibulbar mass with expulsive hemorrhage. Arch Ophthalmol 1984; 102:1523-7.

18. Orellana J, Moura RA ,Font RL, Boniuk M, Murphy D. Medulloepithelioma diagnosed by ultrasound and vitrous aspirate. Electron microscopic observations. Ophthalmology 1983; 90:1531-9.

19. Kivela $T$, Tarkkanen A. Recurrent medulloepithelioma of the ciliary body. Immunohistochemical characteristics. Ophthalmology 1988;95:1565-75.

20. Jose AS, Alfred B, Daniel MA. Pathology of the retina and vitreous. In: Daniel MA, Frederick AJ . Principles and practice of ophthalmology. 1994; 4:2261-66.

21. Spencer WH. Ophthalmic pathology. 3rd edition. 1986:1247-55. 